\title{
Functional Involvement of Reproductive Tracts on Sperm
}

\section{Physiology}

\author{
Wang TE ${ }^{1,2}$, Lai YH ${ }^{1,2}$ and Tsai PSJ 1,2,3,* \\ 1Department of Veterinary Medicine, National Taiwan University, Taiwan \\ ${ }^{2}$ Graduate Institute of Veterinary Medicine, National Taiwan University, Taiwan \\ ${ }^{3}$ Research Center for Developmental Biology and Regenerative Medicine, National \\ Taiwan University, Taiwan
}

\section{Mini Review}

Volume 2 Issue 1

Received Date: February 01, 2017

Published Date: February 15, 2017

*Corresponding author: Pei-Shiue Jason Tsai, Research Center for Developmental Biology and Regenerative Medicine, National Taiwan University, 10617 Taipei, Taiwan, Tel: 8862 33661290; Email: psjasontsai@ntu.edu.tw

Keywords: Reproductive tract; Sperm

\section{Introduction}

Fertilization is an event that involves highly dynamic intra- and intercellular processes which enable the merger of two gametes with the aim to ultimately form a new organism. Preparative changes are required in both gametes prior to fertilization since freshly ejaculated spermatozoa and germinal vesicle (GV) stage arrested oocytes are not capable to form a zygote [1,2]. Constant remodelling on the sperm membrane surface during epididymal maturation and oviductal transition allow spermatozoa to become functional mature, and only functionally matured sperm can achieve successful fertilization [3-6]. Before spermatozoon meets the oocyte, an extensive and continuous reorganization called capacitation enables morphologically mature sperm cells to acquire the ability to fertilize the oocyte, this reorganization of proteins and lipids in the sperm plasma membrane (PM) results in the assemblage of functional membrane protein complexes and the aggregation of membrane microdomains (membrane rafts) [7-10]; the subsequent activation of signalling pathways are also critical for the spermatozoa to undergo a sperm-specific type of exocytosis (the acrosome reaction), this calciumdependent multipoint fusion of the PM and the outer acrosome membrane (OAM) at an extended area of the sperm head surface occurs once in the life span of a sperm cell and the subsequent release of acrosomal enzymes is thought to be essential for sperm penetration of the oocyte's zona pellucida (ZP) [2,11]. Aberration of any of these processes will lead to the failure of fertilization. To ensure spermatozoa capacitate and undergo acrosome reaction at the right time and right place (normally at the ampulla region of the oviduct), it is essential to understand the regulation of sperm activation upon their residence in the reproductive tracts.

Sperm activation generally requires (1) the removal of de-capacitation factors that cover the sperm head membrane surface, (2) increase of sperm membrane fluidity via the removal of albumin on the sperm membrane surface, and (3) alkalization of luminal fluid (increase in bicarbonate concentration). To prevent/minimize unwanted capacitation and spontaneous acrosome reaction, interactions between sperm cells with the epithelium of the reproductive tract is therefore crucial to keep spermatozoa in a quiescent state. It has known that epididymal epithelium bestow proteins and molecules onto sperm membrane surface via epididymosomes (ranging from 90-300 nm) [12]. Although mechanisms of epididymal epithelium to sperm protein transfer is not fully understood, it is generally believed that this sperm-epithelium interaction modulates the activities of specific ion channels (e.g. via 


\section{Open Access Journal of Veterinary Science \& Research}

V-ATPase or $\mathrm{Ca}^{2+}$-ATPase) or to mask sperm membrane receptors that further stabilize sperm membrane structure and inactivate sperm activities [13-15].

Besides the addition of de-capacitation factors from the epididymis and seminal vesicles, fine adjustment of luminal $\mathrm{pH}$ is equally important to regulate sperm activities [16,17]. Epididymis consists of 4 major cell types, narrow cells (at the initial segment), clear cells (present at the caput to cauda), principal cells and basal cells (present throughout the epididymis) [18]. Both narrow cells and clear cells are known to have V-ATPase that is responsible for maintaining acidic luminal microenvironment, this acidified epididymal lumen is characterized with low amount of bicarbonate $(<5 \mathrm{mM})$. Interestingly, upon sperm entering the female reproductive tract, a shift in bicarbonate concentration $(>15 \mathrm{mM})$ initiates sperm specific signaling pathway that involves in the increase of sperm-specific soluble adenylyl cyclase (sAC), cyclic AMP, protein kinase A, tyrosine kinases [19]. Changes mentioned about results in the increase in glycolysis, hyper activated motility as well as sperm-zona binding affinity.

It is known that spermatozoa reside for days to weeks in the caput and corpus region of the epididymis before their "storage site" at the cauda epididymis, therefore is it not surprise that if epididymis would function as an additional check point for sperm quality control [20]. While most of the attentions focus on molecules that activate or deactivate sperm activities during sperm transition in the epididymis, much less attention is paid on whether epididymis or seminal vesicle/fluid-origin proteins, besides facilitate sperm maturation, also participates in sperm selection process that pre-screen fertilization potential or membrane integral of residing spermatozoa. Systemic investigation may further shed light on this yet to be identified functional relevance of epididymis on sperm physiology.

\section{References}

1. Yanagimachi $R$ (1994) Mammalian Fertilization $2^{\text {nd }}$ (Edn.) New York: Raven Press.

2. Okabe M (2014) Mechanism of fertilization: a modern view. Experimental animals / Japanese Association for Laboratory Animal Science 63(4): 357-365.

3. Rodriguez-Martinez H (2007) Role of the oviduct in sperm capacitation. Theriogenology 68(1): S138-146.

Pei-Shiue JT, et al. Functional Involvement of Reproductive Tracts on Sperm Physiology. J Vet Sci Res 2017, 2(1): 000125.
4. Suarez SS (2008) Regulation of sperm storage and movement in the mammalian oviduct. The International journal of developmental biology 52(56): 455-462.

5. Tsai PS, Gadella BM (2009) Molecular kinetics of proteins at the surface of porcine sperm before and during fertilization. Society of Reproduction and Fertility supplement 66: 23-36.

6. Kuo YW, Li SH, Maeda K, Gadella BM, Tsai PS (2016) Roles of the reproductive tract in modifications of the sperm membrane surface. J Reprod Dev 62(4): 337343.

7. Tsai PS, Garcia-Gil N, van Haeften T, Gadella BM (2010) How pig sperm prepares to fertilize: stable acrosome docking to the plasma membrane. PloS one 5(6): e11204.

8. Tsai PS, De Vries KJ, De Boer-Brouwer M, Garcia-Gil N, Van Gestel RA, et al. (2007) Syntaxin and VAMP association with lipid rafts depends on cholesterol depletion in capacitating sperm cells. Molecular membrane biology 24(4): 313-324.

9. Tsai PS, Brewis IA, van Maaren J, Gadella BM (2012) Involvement of complexin 2 in docking, locking and unlocking of different SNARE complexes during sperm capacitation and induced acrosomal exocytosis. PloS one 7(3): e32603.

10. Boerke A, Tsai PS, Garcia-Gil N, Brewis IA, Gadella BM (2008) Capacitation-dependent reorganization of microdomains in the apical sperm head plasma membrane: functional relationship with zona binding and the zona-induced acrosome reaction. Theriogenology 70(8): 1188-1196.

11. Florman HM, Jungnickel MK, Sutton KA (2008) Regulating the acrosome reaction. The International journal of developmental biology 52(5-6): 503-510.

12. Paunescu TG, Shum WW, Huynh C, Lechner L, Goetze $B$, et al. (2014) High-resolution helium ion microscopy of epididymal epithelial cells and their interaction with spermatozoa. Molecular human reproduction 20(10): 929-937.

13. Kim B, Roy J, Shum WW, Da Silva N, Breton S (2015) Role of testicular luminal factors on Basal cell elongation and proliferation in the mouse epididymis. Biology of reproduction 92(1): 9. 


\section{Open Access Journal of Veterinary Science \& Research}

14. Shum WW, Ruan YC, Da Silva N, Breton S (2011) Establishment of cell-cell cross talk in the epididymis: control of luminal acidification. J Androl 32(6): 576586.

15. Kirichok Y, Navarro B, Clapham DE (2006) Whole-cell patch-clamp measurements of spermatozoa reveal an alkaline-activated $\mathrm{Ca}^{2+}$ channel. Nature 439(7077): 737-740.

16. Leemans B, Gadella BM, Stout TA, Nelis H, Hoogewijs M, Van Soom A (2015) An alkaline follicular fluid fraction induces capacitation and limited release of oviduct epithelium-bound stallion sperm. Reproduction 150(3): 193-208.
17. Nishigaki $\mathrm{T}$, Jose $\mathrm{O}$, Gonzalez-Cota $\mathrm{AL}$, Romero $\mathrm{F}$, Trevino CL, Darszon A (2014) Intracellular pH in sperm physiology. Biochem Biophys Res Commun 450(3): 1149-1158.

18. Cornwall GA (2009) New insights into epididymal biology and function. Human Reproduction Updates 15(2): 213-227.

19. Brewis IA, Moore HD, Fraser LR, Holt WV, Baldi E, et al. (2005) Molecular mechanisms during sperm capacitation. Human fertility 8(4): 253-261.

20. Cornwall GA, von Horsten HH, Swartz D, Johnson S, Chau K, et al. (2007) Extracellular quality control in the epididymis. Asian J Androl 9(4): 500-507. 